\title{
Levantamento das afecções ocorridas nos cavalos utilizados em equoterapia no período de 2006 a 2010 em Uruguaiana-RS
}

\section{A review of hippoterapy horse diseases from 2006 to 2010 in Uruguaiana-RS}

\author{
Mayara Nóbrega Gomes da Silva, ${ }^{*}$ Claudia Acosta Duarte, ${ }^{* *}$ Natália Picoli Folchini, ${ }^{*}$ Maria Lígia de Arruda Mistieri, ${ }^{* *}$ \\ Guilherme S. Rodrigues de Freitas, ${ }^{* * *}$ Luis Antônio Duarte Sodré ${ }^{* * * *}$
}

\begin{abstract}
Resumo
O presente trabalho objetivou realizar o levantamento das afecções observadas no período de 2006 a 2010 nos cavalos do Centro de Equoterapia de Uruguaiana "General Fidélis", RS. Avaliaram-se fichas clínicas de 17 equinos, com média de 15,3 anos de idade, mantidos a campo. Os cavalos eram utilizados em seis sessões de 30 minutos de equoterapia, duas vezes por semana. Verificaram-se 47 casos de enfermidades nos animais. Destes, 61,7\% acometeram o sistema tegumentar, observandose principalmente casos clínicos de feridas e, 23,4\% o sistema locomotor, sendo a tendinite a maior ocorrência. Além desses sistemas, constataram-se $8,5 \%$ de enfermidades oftálmicas, $4,3 \%$ do sistema respiratório e $2,1 \%$ vinculadas ao sistema digestório. Concluiu-se que, apesar da casuística pequena, a maior porcentagem das afecções foi verificada nos sistemas tegumentar e locomotor, os quais são de relevância expressiva para a execução da equoterapia, podendo suas alterações comprometer o bom desempenho dessa prática terapêutica. Dessa forma, nota-se a necessidade de estudos complementares visando, principalmente, à prevenção dessas afecções.
\end{abstract}

Palavras-chave: equino, enfermidades, casuística.

\begin{abstract}
The present work aimed to enumerate equine diseases observed from 2006 to 2010 in "General Fidelis" Hippoterapy Center in Uruguaiana-RS. Clinical files of 17 horses with average of 15,3 years old maintained at the field were evaluated. The animals were submitted to 6 sessions of 30 minutes of hippotherapy twice a week. Forty seven cases of disease were found in these animals. $61,7 \%$ of these cases affected the integumentary system. It was observed especially wounds cases. $23,4 \%$ affected the locomotor system having tendinitis as the main occurrence. $8,5 \%$ of them were ophthalmic occurrences, $4,3 \%$ were alterations of the respiratory system and $2,1 \%$ linked to the digestive system. It was concluded that despite the small sample, the higher percentage of diseases were verified in the integumentary and locomotor system which are of significant importance for the execution of hippotherapy. They can also implicate the good performance of this therapeutic practice. Therefore it is noted the need of further studies aiming especially the prevention of these diseases.
\end{abstract}

Keywords: equine, diseases, review.

\section{Introdução}

A Equoterapia é um método terapêutico e educacional em que o cavalo é utilizado para o benefício de pacientes com necessidades especiais (Brilinger, 2005; Pierobon, 2005). A técnica promove uma conexão entre animal-paciente que transmite estímulos motores e sensoriais, além de um ajuste da respiração que se torna ritmada, e da postura, que ativa o cérebro do praticante, levando-o a se modelar corretamente sobre o cavalo (Pierobon e Galetti, 2008).
A terapia baseia-se no movimento tridimensional representado pelos deslocamentos para frente e para trás, para um lado e para o outro e para cima e para baixo, associado a movimentos rotacionais da cintura pélvica do cavaleiro, propiciado pela andadura do equino ao passo (Wickert, 1999).

No cavalo, o centro de gravidade situa-se, de forma geral, na porção medial do gradil costal, caudal a região que separa os terços cranial e médio do corpo. Em razão disso, os membros torácicos suportam de 60 a $65 \%$ do peso corporal.

* Graduação em Medicina Veterinária - Universidade Federal do Pampa, campus Uruguaiana-RS.

** Discente Adjunta da Faculdade de Medicina Veterinária da Universidade Federal do Pampa, campus Uruguaiana-RS. BR 472 - km 592 - Caixa Postal 118 - Uruguaiana - RS - CEP: 97500-970.

*** Departamanto Médico Veterinário do Círculo Militar de Uruguaiana-RS, Brasil.

**** Centro de Equoterapia de Uruguaiana "General Fidélis".

A quem enviar a correspondência. E-mail: claudiaduarte@unipampa.edu.br 
Em determinadas raças, observa-se, no entanto, que o cavalo possui a garupa mais alta que a cernelha e desloca seu centro de gravidade ainda mais cranial (Stashak, 2006), como nas raças campeiro (McManus et al., 2005) e brasileiro de hipismo (Angeli et al., 2011). Isto induz o praticante a realizar a adução e rotação interna de quadril (Pierobon, 2005). Entretanto, existem raças que possuem a garupa mais baixa que a cernelha, deslocando seu centro de gravidade mais caudal, como equinos da raça Mangalarga Marchador (Cabral et al., 2004). Contudo, os deslocamentos desejados ao praticante só serão transmitidos pelo animal se seu centro de gravidade coincidir com o do cavaleiro (Pacchiele, 1999).

A Equoterapia é formulada de modo individual, dependendo dos objetivos traçados para cada praticante, respeitando seus limites e não o expondo a situações perigosas. De acordo com isso, cada cavaleiro necessita de um determinado tipo de passo, frequência e velocidade proporcionada pelo animal.

$O$ equino pode ser utilizado em diferentes modalidades esportivas, sendo necessária conformação física e preparo específicos. Porém, independentemente do objetivo esperado, deve existir manejo nutricional e sanitário adequado que supram suas necessidades fisiológicas de acordo com o esforço a que for submetido em suas atividades.

Animais que executam atividades próximas ao seu limite físico, como cavalos de competição de alto nível, podem ser acometidos por alterações, principalmente, no aparelho locomotor e ter, assim, seu desempenho afetado negativamente (Canto et al, 2006).

Em decorrência de provas em que os animais que utilizam paradas deslizantes e bruscas, alterações abruptas de direção, giros rápidos e esbarros longos, verificam-se principalmente artrite precoce de jarrete, síndrome do navicular e fratura de quartela (Stashak, 2006). Já em cavalos de polo, ocorrem principalmente enfermidades no sistema articular, ligamentar e tendíneo das regiões cárpicas e metacarpofalangeanas (Abreu et al., 2011). Em contrapartida, em cavalos de corrida, uma das articulações mais afetadas é o carpo, apresentando enfermidades como sinovite, capsulite, osteoartrite e tenossinovite do tendão extensor do carpo (Kawkak, 2004). Afecções nas articulações femorotibial e femoropatelar, síndrome do navicular, osteoartrite társica distal e desmite proximal do suspensório são mais observadas em cavalos de rédeas, rodeio, apartação e tambor (Abreu et al., 2011). Como normalmente os animais utilizados em equoterapia são advindos de doação, é fundamental o conhecimento da origem e trabalho prévio dos cavalos, bem como um exame criterioso antes de seu emprego nessa forma terapêutica.

$\mathrm{Na}$ Equoterapia, o cavalo requer características especiais para ser utilizado que, segundo Rocha et al. (2002), incluem a docilidade, personalidade tranquila, andamento regular e firme e estatura média de até $155 \mathrm{~cm}$, já que os praticantes sentemse mais seguros quando na mesma altura do profissional que os conduz. Além das particularidades citadas, o animal deve estar em boas condições físicas, sanitárias e nutricionais, para que haja o sucesso na realização desta terapia, e não coloque a saúde dos demais animais e de seres humanos em risco (Homem, 1999; Aguiar, 2004).

A equoterapia mostra-se eficaz para os praticantes com diversas enfermidades motoras, psicológicas ou mentais, e em razão disso, este método terapêutico tem sido cada vez mais estudado, visando seu maior aprimoramento e melhores resultados. Entretanto, sendo a higidez do animal extremamente importante para o sucesso desta terapia, o estudo do equino torna-se indispensável. Assim, a verificação das alterações ocorridas nos cavalos é fundamental para a promoção do tratamento e prevenção das afecções, proporcionando melhora na técnica de equoterapia e gerando mais qualidade de vida às pessoas e aos animais.

Por conseguinte, o objetivo deste trabalho foi realizar o levantamento das afecções ocorridas nos cavalos utilizados no período de 2006 a 2010 no Centro de Equoterapia de Uruguaiana General Fidélis, do município de Uruguaiana-RS.

\section{Materiais e métodos}

Foram utilizados para o levantamento das afecções 17 cavalos de 6 a 23 anos de idade. Dentre eles, nove animais eram da raça crioula, um meio-sangue com Crioulo, dois equinos meio- sangue com Puro-sangue inglês e cinco animais sem raça definida. Todos os animais eram pertencentes ao Centro de Equoterapia de Uruguaiana General Fidélis, do Círculo Militar de Uruguaiana$\mathrm{RS}$, onde permaneciam a campo, com alimentação à base de pasto nativo e vermifugados a cada três meses.

Os animais utilizados no estudo realizavam as atividades de equoterapia duas vezes por semana, sendo sete sessões por dia com duração de, aproximadamente, 30 minutos cada. $\mathrm{O}$ procedimento ocorria com a utilização simultânea dos animais em um galpão com piso de areia.

O levantamento das afecções foi efetuado verificando-se o prontuário de atendimento dos equinos de equoterapia do Círculo Militar de Uruguaiana, entre o período de 2006 a 2010. Os dados obtidos foram compilados e obtidas as porcentagens.

\section{Resultados}

Após análise das fichas de atendimento dos cavalos de equoterapia do período proposto no presente trabalho, foram verificados 47 casos de afecções (Tabela 1). Constatou-se que 29 afecções $(61,7 \%)$ ocorreram no sistema tegumentar, sendo $83 \%$ de feridas (vinte e quatro casos), $7 \%$ de papiloma (dois casos), $7 \%$ de micose (dois casos), e 3\% (um caso) de doença da linha branca; $23,4 \%$ dos equinos acometidos exibiram enfermidades vinculadas ao sistema locomotor, sendo constatados dez casos (91\%) de tendinite, $60 \%$ (seis casos) no membro torácico e $40 \%$ no membro pélvico (quatro casos). E ainda neste sistema, verificou-se um caso de luxação na patela, que representou $9 \%$. Foram encontrados quatro casos $(8,5 \%)$ de alterações oftálmicas, sendo que a metade das afecções foi de conjuntivite e a outra de úlcera de córnea. Os dois casos de alterações do sistema respiratório (4,3\%) tiveram diagnóstico clínico de influenza equina. Além destes, evidenciou-se um caso $(2,1 \%)$ de alterações no sistema digestório, sendo este de cólica espasmódica.

\section{Discussão}

O número maior de casos foi constatado no sistema tegumentar, principalmente com a verificação de feridas, que são definidas como qualquer alteração na integridade anatômica da pele (Garros et al., 2006; Paganela et al., 2009). O manejo utilizado com esses animais favoreciam tais ocorrências. Rotineiramente, os animais eram presos próximos uns aos outros antes da 
Tabela 1: Correlação entre período de ocorrência e enfermidades observadas nos animais utilizados em equoterapia de 2006 a 2010 no Centro de Equoterapia de Uruguaiana General Fidélis - Uruguaiana-RS

\begin{tabular}{|c|c|c|c|c|c|c|c|c|c|c|}
\hline Animal & $1^{\circ}$ semestre & $2^{\circ}$ semestre & $1^{\circ}$ semestre & $2^{\circ}$ semestre & $1^{\circ}$ semestre & $2^{\circ}$ semestre & $1^{\circ}$ semestre & $2^{\circ}$ semestre & $1^{\circ}$ semestre & $2^{\circ}$ semestre \\
\hline & 2006 & 2006 & 2007 & 2007 & 2008 & 2008 & 2009 & 2009 & 2010 & 2010 \\
\hline \multirow[t]{2}{*}{1} & $\begin{array}{l}\text { Luxação de } \\
\text { patela }\end{array}$ & Tendinite & & & & & & & & \\
\hline & Ferida & & & & & & & & & \\
\hline 2 & $\begin{array}{l}\text { Cólica espa- } \\
\text { mótica }\end{array}$ & $\begin{array}{l}\text { Úlcera de córnea } \\
\text { e Doença da } \\
\text { linha branca }\end{array}$ & & & & & & & & \\
\hline 3 & & & Ferida & & Ferida & & $\begin{array}{l}\text { Conjuntivite } \\
\text { Úlcera de } \\
\text { córnea }\end{array}$ & & Ferida & Tendinite \\
\hline \multirow[t]{2}{*}{4} & & & & Ferida & & & & & & \\
\hline & & & & Micose & & & & & Conjuntivite & Micose \\
\hline 5 & & & & Tendinite & & & & & & $\begin{array}{l}\text { Influenza } \\
\text { equina }\end{array}$ \\
\hline 6 & & & & & $\begin{array}{l}\text { Ferida e } \\
\text { miíase }\end{array}$ & & & & & \\
\hline 7 & & & & & & $\begin{array}{c}\text { Dois casos de } \\
\text { feridas Miíase } \\
\text { Tendinite }\end{array}$ & & & & \\
\hline 8 & & & & & & Ferida & & & & \\
\hline 9 & & & & & & $\begin{array}{c}\text { Dois casos } \\
\text { de ferida } \\
\text { Tendinite }\end{array}$ & & & Miíase & \\
\hline 10 & & & & & & Ferida & & & & \\
\hline 11 & & & & & & & & Papiloma & Papiloma & $\begin{array}{l}\text { Influenza } \\
\text { equina }\end{array}$ \\
\hline 12 & & & & & & & & & Ferida & Ferida \\
\hline 13 & & & & & & & & & Ferida & Tendinite \\
\hline 14 & & & & & & & & & $\begin{array}{l}\text { Dois casos de } \\
\text { míase }\end{array}$ & \\
\hline 15 & & & & & & & & & Ferida & \\
\hline 16 & & & & & & & & & & $\begin{array}{l}\text { Três casos de } \\
\text { ferida }\end{array}$ \\
\hline 17 & & & & & & & & & & Tendinite \\
\hline
\end{tabular}

atividade de Equoterapia e, durante as sessões, que eram feitas em um galpão, diversos animais eram utilizados concomitantemente, aumentando a chance de ocorrência de lesões traumáticas. E, após o término das sessões, os animais eram soltos a pasto, onde estavam sujeitos a diversas causas de lesões como coices e traumas em cercas.

Além disso, é importante ressaltar que 60,9\% dos casos de feridas foram observados nos locomotores, o que pode ter interferido diretamente na andadura dos cavalos.

Seis animais apresentaram miíase na região ferida, sendo que duas ocorreram na região perianal, duas na região torácica e três no membro pélvico. Segundo McGavin e Zachary (2009), a miíase decorre da infestação de moscas nos tecidos que são atraídos pelo odor exalado da pele úmida e suja de urina, fezes ou com secreções corpóreas. Adicionalmente, Pires (2008) cita a necessidade da existência do ferimento para o desenvolvimento das larvas. As miíases verificadas foram provenientes das feridas e, provavelmente, tenham tido facilidade de ocorrência, pois os animais ficavam livres a pasto sujeitos a sujidade e umidade constantes e, muitas vezes, sem inspeção frequente.
Outras afecções do sistema tegumentar com menor casuística foram as micoses e papilomas, ambas diagnosticadas clínica e terapeuticamente, contudo, sem a realização de provas laboratoriais. A micose ocorre com maior frequência em animais com a imunidade e resistência comprometidas devido a doenças sistêmicas debilitantes ou quando são tratados com glicocorticoides ou antibióticos de amplo espectro (McGavin e Zachary, 2009). Além de se tratar de animais idosos, os cavalos da equoterapia, dependendo da época do ano, eram expostos à escassez de pasto, o que pode favorecer na diminuição da resistência orgânica e aparecimento deste tipo de lesão. $O$ tratamento foi realizado com soluções à base de iodo, o qual se mostrou efetivo, assim como relatado por Pereira et al. (2006).

A papilomatose, como explicitam Jones et al. (2000), é uma neoplasia benigna da epiderme, ocasionadas por Papilomavirus contendo DNA, que induzem a proliferação das células basais da derme, resultando em projeções papilares de tecido conjuntivo fibrovascular. A infecção pelo Papilomavirus se dá através de contato direto com a pele lesionada de animais já infectados. Dessa forma, pode-se sugerir sua relação com 
os casos encontrados nesse levantamento, tendo em vista a grande quantidade de feridas verificadas e o contato com o vírus na região. Para o tratamento foi utilizado clorobutanol intralesional, o qual produziu bons resultados, como citado por Santin e Brito (2004).

Um caso de doença da linha branca foi observado e, como explica Stashak (2006), a lesão forma uma abertura na linha branca, permitindo que uma infecção atinja as estruturas sensíveis do casco. Secundário a esta, a claudicação é um sinal clínico, que varia conforme o local de entrada da infecção e de sua intensidade. Pode estar relacionada com o fato de os animais ficarem mantidos a pasto, podendo haver pedras que lesionem esta região do casco, ou ao piso de areia que, em decorrência da umidade, pode favorecer a infecção.

A segunda maior casuística foi verificada no sistema locomotor, com a observação de 10 casos de tendinite. Também compondo este sistema, foram detectados casos de luxação de patela.

Conforme Thomassian (2005), a tendinite pode acometer tendões flexores dos membros, gerando um processo inflamatório. As causas dessa enfermidade são determinadas, principalmente, pelo esforço exacerbado sofrido pelos tendões e articulações causando distensão das fibras que podem romper e gerar uma reação inflamatória local. Pode também decorrer de lesões traumáticas agudas, que causam a descontinuidade do tendão.

A tendinite foi constatada em seis animais nos membros torácicos e em quatro no membro pélvico, o que corrobora com Stashak (2006), que relata que as lesões são mais frequentes nos membros torácicos.

A falta de preparo do animal para certos exercícios físicos em determinadas situações, podem acarretar a lesão nos tendões. Neste estudo o uso de piso de areia para a realização das sessões sem a adequação do animal através do treinamento físico pode ser uma possível causa desta enfermidade. Entretanto, segundo Godoy e Neto (2007), para o desencadeamento desta enfermidade faz-se necessário à formação de microlesões nas fibras tendíneas decorrentes de múltiplas distensões submáximas causadas pelo desempenho atlético, o que não ocorre com os animais de equoterapia, já que o esforço físico exigido deles é baixo.

Por outro lado, antes de serem utilizados em Equoterapia, os animais estudados eram submetidos a outras atividades físicas como a prática do Polo. Estudos acerca deste esporte mostram que dentre as principais afecções encontram-se lesões de ligamentos e tendões (Abreu et al., 2011). Tendinites crônicas podem acometer a elasticidade das fibras tendíneas, acabando por comprometer sua função, podendo advir de subsequentes quadros de recidiva da lesão (Barreira, 2005). Desta forma, esta enfermidade pode estar relacionada com lesões crônicas advindas do esporte praticado anteriormente.

No caso da luxação de patela, ou também chamada de Fixação Superior da Patela (FST), ocorre o travamento da patela no epicôndilo medial do fêmur impedindo a flexão do membro afetado. Isto se dá quando a patela perde a relação articular e o ligamento patelar médio desliza-se ao suco femoral impedindo que esta volte a sua posição fisiológica (Faria, 2007). Uma anormalidade na relação anatômica dos ossos fêmur e tíbia, que se traduz pelo ângulo imperfeito da articulação femorotibiopatelar, tornando o membro mais "reto", predispõe esta luxação (Godoy e Neto, 2007). Cavalos não treinados e com pouca musculatura na região do joelho são sensíveis à ocorrência desta afecção, além de animais com alto condicionamento físico que, por alguma razão, necessitem pausar suas atividades e perdem, de forma repentina, musculatura e tono dos ligamentos patelares. Em decorrência disto, o cavalo altera seu modo de andar, claudica e não apoia o membro corretamente (Stashak, 2006). O animal que apresentou esta afeccção era advindo de atividades esportivas de alta intensidade e passou a participar somente da equoterapia, gerando perda muscular repentina. Como forma de tratamento, foi realizado reforço da musculatura do membro pélvico e o animal não apresentou mais a luxação de patela.

Das enfermidades oftálmicas, observaram-se dois casos de conjuntivite e dois de úlcera de córnea, sendo que um animal apresentou conjuntamente as duas afecções. A conjuntivite é um processo inflamatório na conjuntiva palpebral que pode ter causa traumática, mecânica, tóxica, alérgica ou infecciosa. Além dessa enfermidade, foram constatados dois casos de úlcera de córnea, que pode ser ocasionada por micro- organismos ou por materiais presentes no ambiente, seja este do solo ou de plantas (Fusco et al., 2007). Os achados oftalmológicos podem estar relacionados com a areia do piso onde são realizadas as atividades de equoterapia, visto que diversos cavalos trabalham ao mesmo tempo, um atrás do outro. Dessa forma, existe a facilidade da lesão mecânica no globo ocular.

No sistema respiratório foram observados dois casos de influenza equina, diagnosticados apenas de forma clínica, sem a constatação laboratorial da doença. Nesta enfermidade, o cavalo apresenta sinais clínicos como tosse seca, descarga nasal serosa, anorexia e edema dos membros. Para que haja a transmissão da enfermidade, parece ser necessário o contato íntimo entre os animais (Weiblen, 2007), o que acontecia nas sessões de equoterapia e quando eram mantidos a pasto. Adicionalmente, salientam-se outros fatores que podem ter corroborado para a ocorrência desta afecção como a idade avançada dos animais, a condição de escassez de pasto, em determinadas épocas do ano, além de não serem equinos vacinados.

Com relação ao sistema digestório, foi constatado um caso de cólica espasmódica, que foi tratado clinicamente. O termo cólica sugere a manifestação de dor abdominal (Thomassian, 2005), que pode advir, segundo Laranjeira e Almeida (2008), de alto consumo de grãos ou de alimentos fermentáveis.

O ambiente, a nutrição, o manejo e as diferentes atividades a que os cavalos da Equoterapia eram ou já foram submetidos determinam sua performance e suas possíveis afecções. Sendo assim, estas podem ter origem multifatorial.

Sabendo-se que a andadura do equino deve produzir movimentos tridimensionais para a obtenção dos efeitos desejáveis da equoterapia, e que há o contato direto entre os equinos e as pessoas praticantes da equoterapia, faz-se necessário que a saúde equina esteja assegurada, livre de doenças locomotoras e sistêmicas, incluindo zoonoses (Wickert, 1999; Pierobon e Galetti, 2008). Portanto, deve haver melhor avaliação dos animais antes de iniciarem a equoterapia, bem como depois de serem submetidos às sessões, visando o diagnóstico precoce das possíveis afecções. Dessa forma, garantindo sua saúde e longevidade e, consequentemente, promovendo os efeitos benéficos da equoterapia aos praticantes.

\section{Conclusão}

Apesar da casuística pequena, a maior porcentagem das afecções foi verificada nos sistemas tegumentar e locomotor, respectivamente, os quais são de relevância expressiva para a execução da equoterapia. 
Sabendo-se que o andar do cavalo e sua saúde em geral são fundamentais para a realização desta terapia, é de fundamental importância que estes animais sejam sempre bem avaliados antes da sua aquisição e mais estudos sejam efetuados no

\section{Referências}

ABREU, H.C. de.; DE LA CÔRTE, F.D.; BRASS, K.E.; POMPERMAYER, E.; LUZ, T.R.R. da; GASPERI, D. de. Claudicação em cavalos Crioulos atletas. Cienc. Rural, v. 41, n. 12, Santa Maria, 2011.

AGUIAR, D. M. Prevalência de anticorpos anti-neospora caninum, anti-brucella abortus e anti-leptospira spp. em bovinos da zona rural do município de Monte Negro, Rondônia: estudo de possíveis fatores de risco. 2004. 120 f. Dissertação (Mestrado) - Instituto de Ciências Biomédicas, Universidade de São Paulo, São Paulo, 2004.

ANGELI, A.L; REIS, A.D.G. dos; BRUSORIO, D.R.; SIMIONI, L.C.; HARTMANN, W. Biometria de cavalos da raça brasileiro de hipismo: Resultados parciais. Revista eletrônica biociências, biotecnologia e saúde. n.1. Paraná, 2011.

BARREIRA, A.P.B. Implante autólogo de células mesenquimais no tratamento de tendinites induzida em equinos: avaliação clínica, ultrassonográfica e imunoistoquímica. 2005. 98 f. Tese (Doutorado) - Faculdade de Medicina Veterinária - Universidade Estadual Paulista "Júlio Mesquita Filho", Botucatu, 2005.

BRILINGER, C.O. A influência da Equoterapia no desenvolvimento motor do portador de Síndrome de Down: estudo de um caso. 2005. 109 f. Trabalho de conclusão de curso - Faculdade de Fisioterapia - Universidade do Sul de Santa Catarina, Tubarão, 2005.

CABRAL, G.C.; ALMEIDA, F.Q.DE; AZEVEDO, P.C.N.DE; QUIRINO, C.R.; SANTOS, E.M. CORASSA, A.; PINTO, L.F.B. Avaliação Morfométrica de Equinos da Raça Mangalarga Marchador: Medidas Angulares. R. Bras. Zootec., v. 33, n. 6, p.1790-1797, 2004.

CANTO, L.S.; LA CORTE, F.D.; BRASS, K.E.; RIBEIRO, M.D. Frequência de problemas de equilíbrio nos cascos de cavalos crioulos em treinamento. Brazilian Journal of Veterinary Research and animal Science, v. 43, n. 4, p. 489-495, 2006.

FARIA, B.D.B. Fixação superior da patela em equinos. 2007. $20 \mathrm{f}$ Monografia - Faculdade de Jaguariúna, Recife, 2007.

FUSCO, M.A; VIEIRA, J.B.; RAMOS, M.T.; PIRES, N.R. Resultados de testes de cultura e antibiograma em seis casos de úlcera corneana em equinos. Archives of Veterinary Science, v.11, n. 3, p. 56-59, 2007.

GARROS, I.C.; CAMPOS, A.C.L.; TÂMBARA, E.M.; TENÓRIO, S.B.; TORRES, O.J.M.; AGULHAM, M.A.; ARAÚJO, A.C.F.; SANTIS-ISOLAN, P.M.B.; OLIVEIRA, R.M. de.; ARRUDA, E.C.M. Extrato de Passiflora edulis na cicatrização de feridas cutâneas abertas em ratos: estudo morfológico e histológico. Acta. Cir. Bras., v. 21, n. 3, p. 55-65, 2006.

GODOY, R.F.; NETO, A.R.T. Claudicação em equinos. In: RIETCORREA, F.; SCHILD, A.L.; LEMOS, R.A.A.; BORGES, J.R.J. Doenças de Ruminantes e Equídeos. 3. ed., v. 2. Santa Maria: Pallotti, 2007. p. 529-569.

HOMEM, V.S.F. Brucelose, leptospirose e tuberculose em Uruará, PA, município da Amazônia oriental. Estudo da população humana e animal 1999. 76 p. Dissertação Departamento de Medicina Veterinária Preventiva e Saúde Animal - Faculdade de Medicina Veterinária e Zootecnia, Universidade de São Paulo, 1999.

JONES, T.C.; HUNT, R.D.; KING N.W. Patologia veterinária. 6. ed. Barueri: Manole, 2000. intuito de desvendar a origem e prevenir as possíveis afecções para que a equoterapia tenha condições de ser cada vez mais eficiente, zelando pelo bem estar humano e animal.

KAWKAK, C.E. The carpus. In: HINCHCLIFF, K. W.; KANEPS, A. J.; GEOR, R. J. Equine sports medicine and surgery. Saint Louis: Saunders, 2004. p.349-367.

LARANJEIRA, P.V.E.H.; ALMEIDA, F.Q. Síndrome cólica em equinos: ocorrência e fatores de risco. Rev. de Ciên. da Vida, RJ, EDUR. v. 28, n. 1, 2008, p. 64-78.

McGAVIN, M.D.; ZACHARY, J.F. Bases da patologia em veterinária. 4. ed. Rio de Janeiro: Elsevier, 2009.

McMANUS, C.; FALCÃO, R.A.; SPRITZE, A.; COSTA, D.; LOUVANDINI, H.; DIAS, L.T.; TEIXEIRA, R.A.; REZENDE, M.J.M.; GARCIA, J.A.S. Caracterização Morfológica de Eqüinos da Raça Campeiro. R. Bras. Zootec., v. 34, n. 5, p. 1553-1562, 2005.

PACCHIELE, C. Equoterapia para reabilitação em pacientes portadores de AVC (Acidente Vascular cerebral). I Congresso Brasileiro de Equoterapia - Coletânea de trabalhos - Associação Brasileira de Equoterapia. Brasília. p.79, nov., 1999.

PAGANELA, J.C.; RIBAS, L.M.; SANTOS, C.A.; FEIJÓ, L.S.; NOGUEIRA, C.E.W.; FERNANDES, C.G. Abordagem clínica de feridas cutâneas em equinos. Revista Portuguesa de Ciências Veterinárias, v.104 (569-572) 13-18, 2009.

PEREIRA, D.I.B.; OLIVEIRA, L.S.S.; BUENO, A.; CAVALHEIRO, A.S.; SCHWENDLER, S.E.; AZEVEDO, M.I.; JÚNIOR, J.C.E.; AGUIAR, L.C.; SANTURIO, D.F.; SANTURIO, J.M.; ALVES, S.H. Surto de Trichophyton equinum var. equinum em eqüinos no sul do Brasil. Ciência Rural, Santa Maria, v. 36, n. 6, p. 1849-1853, 2006.

PIEROBON, J.C.M. Apostila Curso de Extensão: Equoterapia - Princípio teórico e abordagem terapêutica. Anhanguera Educacional - UNIFIAN, Leme. p. 10, out., 2005.

PIEROBON, J.C.M.; GALETTI, F.C. Estímulos sensório-motores proporcionados ao praticante de equoterapia pelo cavalo ao passo durante a montaria. Ensaios e Ciência: Ciências biológicas, agrárias e da saúde. São Paulo, vol. XII, n. 2, dez., 2008.

PIRES, M.S. Miíases Umbilicais em Bezerros Nelore RecémNascidos: Predisposição em Dois Cruzamentos Raciais Criados no Sistema de Manejo Voisin no Rio de Janeiro e Avaliação de Medidas Profiláticas em Criação Extensiva no Pantanal Sul-MatoGrossense. 2008. 82 p. Dissertação de mestrado em Ciências Veterinárias, Área de concentração em Sanidade Animal - Universidade Federal Rural do Rio de Janeiro, Rio de Janeiro, 2008.

ROCHA, F.L.; FRANCIS, B.A.A; SOUZA, M.M.O.; FRANCIS, D.G. Fatores de importância na prática de Equoterapia como projeto de extensão. I Congresso Brasileiro de Extensão Universitária. Nov. 2002.

SANTIN, A.P.I.; BRITO, L.A.B. Estudo da papilomatose cutânea em bovinos leiteiros: comparação de diferentes tratamentos. Revista Ciência Animal Brasileira, v. 5, n. 1, 2004.

STASHAK, T.S. Claudicação em eqüinos segundo Adams. 5. ed. São Paulo: Roca, 2006.

THOMASSIAN, A. Enfermidades dos cavalos. 4. ed. São Paulo: Varela, 2005.

WEIBLEN, R. Influenza equina. In: RIET-CORREA, F.; SCHILD, A.L.; LEMOS, R.A.A.; BORGES, J.R.J. Doenças de Ruminantes e Eqüídeos. 3. ed., v. 1. Santa Maria: Pallotti, 2007. p.152-159.

WICKERT, H. O cavalo como instrumento cinesioterapêutico. I Congresso Brasileiro de Equoterapia - Coletânea de trabalhos Associação Nacional de Equoterapia. Brasília, DF, p. 101, nov. 1999. 